\title{
PENGARUH PROFITABILITAS, RISIKO KREDIT, LIKUIDITAS, DAN EFISIENSI OPERASIONAL TERHADAP KECUKUPAN MODAL PADA BPR KABUPATEN KLUNGKUNG
}

\author{
Ni Putu Ayu Ria Agustini' \\ Luh Gede Sri Artini ${ }^{2}$ \\ ${ }^{1,2}$ Fakultas Ekonomi dan Bisnis Universitas Udayana (Unud), Bali, Indonesia \\ e-mail : riaagustini48@gmail.com
}

\begin{abstract}
ABSTRAK
Penelitian ini bertujuan untuk mengetahui pengaruh profitabilitas, risiko kredit, likuiditas dan efisiensi operasional terhadap kecukupan modal pada Bank Perkreditan Rakyat Kabupaten Klungkung pada tahun 2013 - 2017. Dalam penelitian ini metode yang digunakan adalah teknik analisis regresi linier berganda. Penelitian ini menggunakan sampel jenuh dengan total sampel sebanyak 5 BPR yang terletak di Kabupaten Klungkung. Berdasarkan hasil analisis yang telah dilakukan, didapat hasil yakni Profitabilitas yang diwakilkan oleh ROA, risiko kredit yang diwakilkan oleh NPL, likuiditas yang diwakilkan oleh LDR, dan efisiensi operasional yang diwakilkan oleh BOPO mendapatkan hasil positif signifikan terhadap kecukupan modal. 76,4 persen kecukupan modal dipengaruhi oleh profitabilitas, risiko kredit, likuiditas dan efisiensi operasional sedangkan sisanya sebesar 23,6 persen dipengaruhi oleh faktor-faktor lain yang tidak dimasukkan kedalam model penelitian.
\end{abstract}

Kata kunci : $R O A, N P L, L D R$, BOPO, kecukupan modal

\begin{abstract}
This study aims to determine the effect of profitability, credit risk, liquidity and operational efficiency towards the capital adequacy ratio in Bank Perkreditan Rakyat which located in Klungkung regency in 2013-2017. In this s tudy the method used is multiple linear regression analysis techniques. This study used a saturated sample with a total sample of 5 $B P R$ located in Klungkung Regency. Based on the results of the analysis that has been done, obtained the results of Profitability represented by ROA, credit risk represented by $N P L$, liquidity represented by $L D R$, and operational efficiency represented by BOPO get significant positive results on capital adequacy. 76.4 percent of the capital adequacy is affected by profitability, credit risk, liquidity and operational efficiency while the remaining 23.6 percent is influenced by other factors not included in the research model.
\end{abstract}

Keyword: ROA, NPL, LDR, BOPO, capital adequacy 
Ni Putu Ayu Ria Agustini, Pengaruh Profitabilitas, Risiko Kredit, Likuiditas...

\section{PENDAHULUAN}

Lembaga keuangan seperti bank memiliki peran penting didalam membangun perekonomian disebuah negara yakni sebagai perantara antara pemilik dana yang menghimpun kelebihan dananya dan menyalurkan dana yang dihimpunnya ke masyarakat. Menurut Kasmir (2015:25) menyebutkan agar masyarakat mau menyimpan uangnya di bank, maka pihak perbankan memberikan timbal balik berupa balas jasa yang akan diberikan kepada si penyimpan. Balas jasa tersebut dapat berupa bunga, bagi hasil, hadiah, pelayanan atau balas jasa lainnya. Menurut Undang Undang No 10 Tahun 1998 terdapat 2 jenis perbankan yakni Bank Umum dan juga Bank Perkreditan Rakyat. Perkembangan bank khususnya Bank Perkreditan Rakyat atau BPR saat ini diawasi dengan ketat dan diatur oleh pemerintah, dan munculah aturan bank seperti SK dir. no.30/12/kep/dir tanggal 30 April 1997 tentang tatacara penilaian tingkat kesehatan BPR.

Tingkat Kesehatan Bank adalah hasil penilaian kondisi Bank yang dilakukan terhadap risiko dan kinerja Bank (PBI NO 13/1/PBI/2011). Tingkat kesehatan bank bisa dihitung menggunakan metode Capital, Assets, Management, Earning, Liquidity, dan Sensitivity to Market Risk atau yang kerap disingkat dengan CAMELS atau dengan metode RGEC yakni Risk, Good Corporate Governance, Earnings, Capital. Bank Perkreditan Rakyat (BPR) yang sehat ditunjukkan dengan kinerja BPR yang bagus, dapat menjaga dan memelihara kepercayaan masyarakat dan yang utama adalah dapat menjalankan kewajibannya 
dengan baik seperti menghimpun dan menyalurkan dana dengan baik dan untuk menjalankan kewajibannya suatu bank memerlukan modal yang mencukupi.

Permodalan merupakan salah satu kendala yang nyata dan sering dialami oleh masyarakat dalam menjalankan aktivitas perekonomiannya, menghadapi permasalahan tersebut maka peranan dari sektor perbankan maupun non bank dalam menghimpun dan menyalurkan dananya sangat berpengaruh terhadap kelancaran ekonomi (Sujana dan Mustanda, 2014). Kecukupan modal dapat diukur dengan menggunakan rasio Capital Adequacy Ratio (CAR). Alasan digunakannya kecukupan modal menjadi variabel dependen adalah karena modal sangat dibutuhkan dalam membiayai kegiatan operasional bank serta modal memiliki peran penting sebagai penyangga kemungkinan terjadinya risiko kerugian.

Tabel 1.

Tingkat CAR, ROA, NPL, LDR, dan BOPO pada BPR se Kabupaten Klungkung periode tahun 2013 - 2017

\begin{tabular}{rrrlll}
\hline Tahun & ROA & \multicolumn{1}{c}{ NPL } & LDR & BOPO & CAR \\
\hline 2013 & $2,61 \%$ & $5,71 \%$ & $80,50 \%$ & $87,52 \%$ & $18.75 \%$ \\
2014 & $2,87 \%$ & $5,57 \%$ & $86,23 \%$ & $85,37 \%$ & $18,85 \%$ \\
2015 & $2,40 \%$ & $6,17 \%$ & $86,43 \%$ & $84,57 \%$ & $17,65 \%$ \\
2016 & $2,27 \%$ & $10,17 \%$ & $83,23 \%$ & $87,37 \%$ & $16,85 \%$ \\
2017 & $2,71 \%$ & $8,56 \%$ & $85,36 \%$ & $86,47 \%$ & $21,27 \%$ \\
\hline
\end{tabular}

Sumber : data diolah, 2018

Pada Tabel diatas dapat terlihat fenomena yang terjadi pada Bank Perkreditan Rakyat se Kabupaten Klungkung pada tahun 2013-2017. Terjadi fluktuasi tingkat ROA, NPL, LDR, BOPO, CAR pada lima tahun periode tersebut. Peneliti memilih Bank Perkreditan Rakyat se Kabupaten Klungkung sebagai 
Ni Putu Ayu Ria Agustini, Pengaruh Profitabilitas, Risiko Kredit, Likuiditas...

lokasi penelitian karena terjadinya fluktuasi nilai CAR, NPL, LDR, ROA dan BOPO. Peneliti ingin mengetahui apakah terdapat pengaruh dari profitabilitas, likuiditas, risiko kredit, efisiensi operasional terhadap kecukupan modal yang terjadi pada BPR se Kabupaten Klungkung selama periode 2013-2017.

Kecukupan modal dapat dipengaruhi oleh profitabilitas. Profitabilitas menunjukkan kemampuan bank didalam memperoleh laba. Profitabilitas memiliki arti penting bagi suatu bank dikarenakan tingkat profitabilitas dapat menggambarkan kinerja suatu bank didalam menghasilkan profit. Return on Asset (ROA) merupakan rasio profitabilitas yang digunakan dalam penelitian ini yaitu perbandingan antara laba sebelum pajak dengan total aset. Alasan digunakannya profitabilitas menjadi variabel independen adalah karena nilai profitabilitas BPR Se Kabupaten Klungkung semakin tahun terus menurun. Profitabilitas yang menurun menandakan laba yang dihasilkan sedikit dan bisa saja disebabkan karena penggunaan atau pengelolaan asset oleh pihak BPR Se Kabupaten Klungkung yang kurang efektif.

Terdapat beberapa penelitian yang menguji apakah ada pengaruh profitabilitas terhadap kecukupan modal. Menurut penelitian yang dilakukan oleh Shaddady dan Moore (2015) mendapatkan hasil profitabilitas memiliki pengaruh positif signifikan terhadap kecukupan modal. Sejalan dengan penelitian yang dilakukan Aktas et al. (2015), Wen (2007), Mekonnen (2015), Fitrianto \& Mawardi (2006), Yuanjuan (2012) mendapatkan hasil yakni profitabilitas memiliki pengaruh positif signifikan terhadap kecukupan modal. Para peneliti lain seperti Natasia (2015) dan Shitawati (2006) mendapatkan hasil penelitian yakni 
profitabilitas memiliki pengaruh yang positif terhadap kecukupan modal. Disisi lain Fatimah (2014) serta Al Tamimi \& Obeidat (2013) mendapatkan hasil yakni profitabilitas memiliki pengaruh negatif signifikan terhadap kecukupan modal.

Risiko kredit juga dapat mempengaruhi kesehatan permodalan bank. Risiko kredit yang dimaksudkan di dalam penelitian ini adalah kredit bermasalah. Non Performing Loan (NPL) adalah rasio yang digunakan untuk mengukur tingkat kredit macet atau bermasalah yang terjadi pada bank. Alasan digunakannya risiko kredit menjadi variabel independen adalah karena risiko kredit atau kredit macet yang dimiliki BPR Se Kabupaten Klungkung setiap tahunnya makin meninggi.

Terdapat beberapa penelitian yang menguji apakah ada pengaruh risiko kredit terhadap kecukupan modal. Hasil penelitian yang ditemukan Yuanjuan (2012) mendapatkan hasil yakni risiko kredit memiliki pengaruh yang negatif terhadap kecukupan modal. Hal ini sejalan dengan penelitian yang dikemukakan oleh Natasia (2015), Shingjergji \& Hyseni (2015), Margaretha dan Diana (2011), Tracey (2011), Abusharba et al. (2013), Pastory et al. (2013). Berbeda dari hasil penelitian diatas, Torki \& Ghazi (2015) dan Bukian (2016) mendapatkan hasil yaitu risiko kredit memiliki pengaruh positif signifikan terhadap kecukupan modal dan Andersson (2013) mendapatkan hasil positif tidak signifikan.

Pengelolaan likuiditas sering sekali menjadi masalah yang rumit didalam kegiatan operasional bank. Likuiditas menggambarkan kemampuan bank dalam memenuhi kewajiban jangka pendeknya. Likuiditas merupakan unsur penting bagi bank, karena dengan likuiditas yang cukup maka bank mampu memenuhi 
Ni Putu Ayu Ria Agustini, Pengaruh Profitabilitas, Risiko Kredit, Likuiditas...

kewajiban jangka pendek dari setiap nasabah (Latumaerissa:2017:213). Rasio yang digunakan untuk mengukur Likuiditas adalah Loan to Deposit Ratio (LDR) yang merupakan perbandingan total kredit yang diberikan dengan total dana pihak ketiga yang dihimpun, semakin besar rasio ini menandakan bahwa meningkatnya penyaluran kredit yang dilakukan oleh bank. Alasan digunakannya likuiditas menjadi variabel independen adalah karena likuiditas merupakan salah satu indikator untuk menilai tingkat kesehatan bank.

Terdapat beberapa penelitian yang menguji apakah ada pengaruh likuiditas terhadap kecukupan modal. Penelitian yang dilakukan oleh Shingjergji dan Hyseni (2015) mendapatkan hasil likuiditas memiliki pengaruh negatif signifikan terhadap kecukupan modal. Penelitian oleh Fitrianto \& Mawardi (2006), Yuanjuan (2012), Natasia (2015), Shitawati (2006), Anjani (2013), Pasiouras et al. (2006) juga mendapatkan hasil likuiditas memiliki pengaruh negatif signifikan terhadap kecukupan modal. Pendapat yang berbeda dikemukakan oleh Maolany (2015), Torki \& Ghazi (2015), Al Tamimi \& Obeidat (2013), Bukian (2016) mendapatkan hasil yakni likuiditas memiliki pengaruh positif signifikan terhadap kecukupan modal. Penelitian lain yang dilakukan oleh Williams (2011) mendapatkan hasil yakni likuiditas memiliki pengaruh positif terhadap kecukupan modal.

Bank menggunakan modal yang dimilikinya di dalam menjalankan kegiatan operasionalnya. Rasio yang digunakan untuk mengukur efisien atau tidaknya bank didalam menjalankan kegiatan operasional dalam suatu bank adalah rasio perbandingan antara biaya operasional terhadap pendapatan operasional (BOPO) 
(Chatarine,2014). Rasio ini menunjukkan seberapa efisiensi suatu bank didalam menjalankan kegiatannya. Semakin kecil biaya operasional maka menunjukkan semakin efisien bank tersebut didalam menggunakan modal yang dimiliki. Alasan digunakannya efisiensi operasional menjadi variabel independen adalah karena nilai efisiensi operasional yang tiap tahun meningkat.

Terdapat beberapa penelitian yang menguji apakah ada pengaruh efisiensi operasional terhadap kecukupan modal. Penelitian oleh Fitrianto dan Marwadi (2006) menemukan efisiensi operasional berpengaruh negatif signifikan terhadap kecukupan modal. Penelitian ini sejalan dengan penelitian Shitawati (2006), Yuliani (2015), Natasia (2015) dan Basse \& Mulazid (2017). Berbeda dari hasil dikemukakan Fatimah (2014), Chatarine (2014) mengatakan bahwa efiensi operasional berpengaruh positif signifikan terhadap kecukupan modal.

Karena terdapatnya perbedaan berdasarkan hasil penelitian sebelumnya, dapat dilihat terdapat research gap di dalam penelitian ini yang masih perlu dikaji lebih dalam lagi guna untuk memperjelas temuan untuk selanjutnya.

Berdasarkan uraian latar belakang, maka didapatkanlah beberapa rumusan masalah di dalam penelitian ini yang dimana dijabarkan sebagai berikut yakni pengaruh profitabilitas, risiko kredit, efisiensi operasional dan likuiditas terhadap kecukupan modal. Berdasarkan uraian latar dan rumusan masalah yang telah dijabarkan, maka tujuan yang ingin dicapai di dalam penelitian ini adalah Untuk mengetahui pengaruh profitabilitas, likuiditas, risiko kredit dan efisiensi operasional terhadap kecukupan modal. 
Ni Putu Ayu Ria Agustini, Pengaruh Profitabilitas, Risiko Kredit, Likuiditas...

Berdasarkan tujuan penelitian diatas diharapkan akan menghasilkan manfaat secara teoritis yang dapat memberikan bukti empiris mengenai faktor-faktor yang berpengaruh terhadap kecukupan modal pada Bank Perkreditan Rakyat se kabupaten Klungkung dan manfaat praktis yaitu penelitian ini dapat menjadi bahan pertimbangan dan evaluasi bagi Bank Perkreditan Rakyat se kabupaten Klungkung dalam menentukan strategi dan dalam mempertahankan/menguatkan kinerja keuangan.

Tujuan akhir yang ingin dicapai oleh setiap bank yang terpenting adalah memperoleh laba atau keuntungan yang maksimal. Untuk mengukur tingkat keuntungan suatu perusahaan digunakan rasio profitabilitas (Kasmir, 2017:196). Profitabilitas merupakan kemampuan bank untuk mendapatkan atau memberikan keuntungan atau laba secara efektif dan efisien. Rasio yang digunakan untuk menghitung profitabilitas adalah Return On Assets (ROA). Semakin besar nilai profitabilitasnya menunjukkan semakin besar laba yang diterima bank dan laba tersebut akan masuk menjadi modal bank yang akan menunjukkan kecukupan modal meningkat.

Terdapat beberapa penelitian yang menguji apakah ada pengaruh profitabilitas terhadap kecukupan modal. Menurut penelitian yang dilakukan oleh penelitian yang dilakukan oleh Shaddady dan Moore (2015), Wen (2007), Mekonnen (2015), Fitrianto \& Mawardi (2006), Yuanjuan (2012) mendapatkan hasil yakni ROA memiliki hubungan positif signifikan terhadap kecukupan modal. Berdasarkan uraian tersebut dapat ditarik hipotesis sebagai berikut :

$\mathrm{H}_{1}$ : Profitabilitas memiliki pengaruh positif signifikan terhadap kecukupan modal. 
Risiko kredit merupakan risiko yang diakibatkan karena debitur gagal dalam memenuhi kewajibannya kepada Bank. NPL (Non Performing Loan) adalah rasio yang digunakan untuk mengukur seberapa besar tingkat kredit bermasalah yang terjadi pada bank. Peningkatan NPL mencerminkan risiko kredit yang ditanggung pihak bank akibat debitur tidak dapat membayar kewajibannya (Bukian \& Sudiartha, 2016). Semakin tinggi nilai NPLnya maka menunjukkan semakin tinggi risiko tidak terbayarnya kewajiban oleh debitur yang mengakibatkan pendapatan menurun dan kecukupan modalpun ikut menurun.

Terdapat beberapa penelitian yang menguji apakah ada pengaruh risiko kredit terhadap kecukupan modal. Menurut penelitian yang dilakukan oleh Natasia (2015), Shingjergji \& Hyseni (2015), Margaretha dan Diana (2011), Tracey (2011), Abusharba et al. (2013), Pastory et al. (2013) mengemukakan hasil yakni risiko kredit memiliki pengaruh negatif signifikan terhadap kecukupan modal. Berdasarkan uraian tersebut dapat ditarik hipotesis sebagai berikut :

$\mathrm{H}_{2}$ : Risiko kredit memiliki pengaruh negatif dan signifikan terhadap kecukupan modal.

Likuiditas merupakan unsur penting bagi bank, karena dengan likuiditas yang cukup maka bank mampu memenuhi kewajiban jangka pendek dari setiap nasabah (Latumaerissa:2017:213). Dalam penelitian ini menggunakan rasio Loan to Deposit Ratio (LDR) untuk mengukur likuiditas. Semakin mampu bank dapat menyerap dana pihak ketiga dari masyarakat dengan banyak, menunjukkan semakin banyak cash yang bank dapatkan untuk bisa menutupi kewajiban dengan baik. Semakin tinggi nilai likuiditas yang dimiliki oleh bank, tentu saja menunjukkan semakin besar pula kecukupan modalnya. 
Ni Putu Ayu Ria Agustini, Pengaruh Profitabilitas, Risiko Kredit, Likuiditas...

Terdapat beberapa penelitian yang menguji apakah ada pengaruh Likuiditas terhadap kecukupan modal yakni Bukian (2016), Maolany (2015), Al Tamimi dan Obeidat (2013), Torki dan Ghazi (2015) mendapatkan hasil yakni likuiditas memiliki pengaruh positif dan signifikan terhadap kecukupan modal. Jika dilihat berdasarkan uraian tersebut maka dapat ditarik hipotesis sebagai berikut :

$\mathrm{H}_{3}$ : Likuiditas memiliki pengaruh positif dan signifikan terhadap kecukupan modal

Bank melakukan kegiatan operasionalnya menggunakan modal yang dimilikinya. Rasio yang digunakan untuk mengukur kinerja operasional dalam suatu bank adalah BOPO. Rasio BOPO ini menunjukkan seberapa efisiensi suatu bank didalam menjalankan kegiatannya. Semakin kecil biaya operasional maka menunjukkan semakin efisien bank tersebut didalam menggunakan modal yang dimiliki.

Terdapat beberapa penelitian yang menguji apakah ada pengaruh BOPO terhadap kecukupan modal yakni Shitawati (2006), Fitrianto dan Marwadi (2006), Yuliani (2015), Basse \& Mulazid (2017) dan Natasia (2015) mendapatkan hasil yakni BOPO memiliki pengaruh negatif signifikan terhadap kecukupan modal. Berdasarkan uraian tersebut dapat ditarik hipotesis :

$\mathrm{H}_{4}$ : Efisiensi Operasional memiliki pengaruh negatif dan signifikan terhadap kecukupan modal 
Berikut adalah kerangka konseptual didalam penelitian ini :

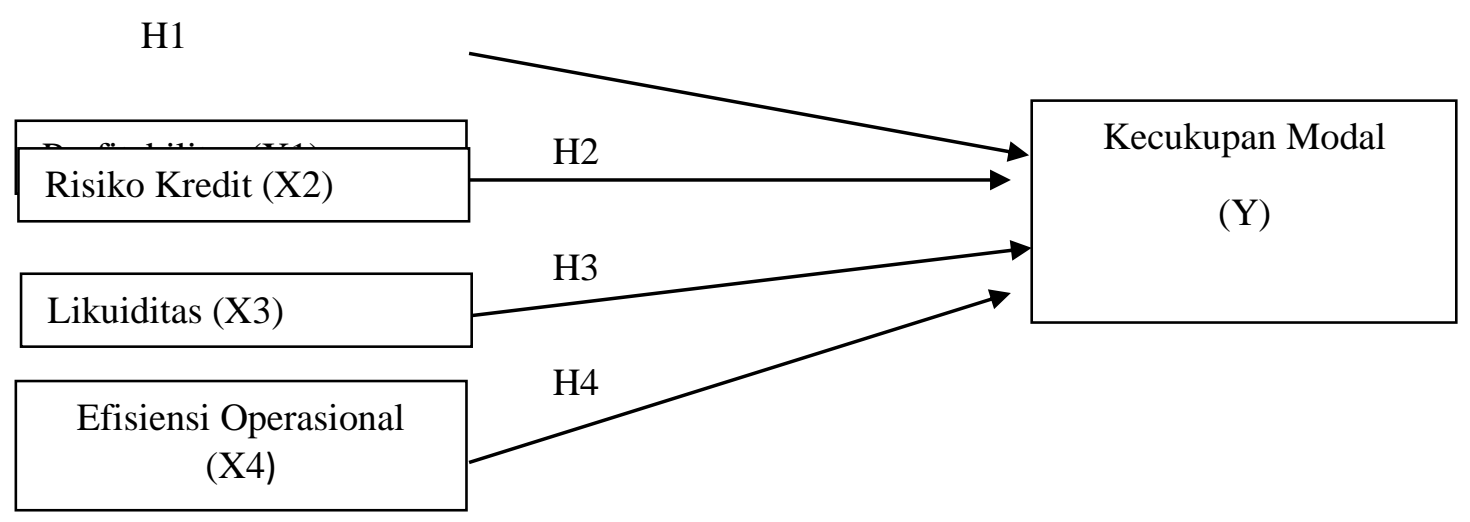

\section{Gambar 1.Pengaruh Profitabilitas, Risiko Kredit, Likuiditas, dan Efisiensi Operasional Terhadap Kecukupan Modal Bank BPR se Kabupaten Klungkung (2013-2017)}

\section{METODE PENELITIAN}

Pada penelitian ini desain yang digunakan adalah desain asosiatif. Penelitian ini menguji pengaruh profitabilitas, risiko kredit, likuiditas dan efisiensi operasional terhadap kecukupan modal. Lokasi penelitian pada penelitian ini adalah Bank Perkreditan Rakyat Kabupaten Klungkung. Objek dari penelitian ini adalah tingkat kecukupan modal BPR se Kabupaten Klungkung pada periode $2013-2017$.

Dilakukannya penelitian ini untuk menguji pengaruh profitabilitas, risiko kredit, likuiditas, efisiensi operasional terhadap kecukupan modal pada BPR Kabupaten Klungkung tahun 2013-2017. Terdapat lima variabel yang terdiri dari 1 variabel dependen (kecukupan modal) dan 4 variabel independen (profitabilitas, risiko kredit, likuiditas, efisiensi operasional). 
Ni Putu Ayu Ria Agustini, Pengaruh Profitabilitas, Risiko Kredit, Likuiditas...

Penelitian ini menggunakan rasio Capital Adequacy Ratio (CAR) untuk mengukur kecukupan modal yaitu perbandingan antara rasio modal dan rasio Aktiva Tertimbang Menurut Risiko (ATMR) pada BPR se Kabupaten Klungkung dalam satuan persentase. Menurut SE BI No 3/30/ DPNP tgl 14 Desember 2001 Capital Adequacy Ratio dapat dirumuskan sebagai berikut :

$\mathrm{CAR}=\frac{\text { Modal }}{A T M R} X 100 \%$

Penelitian ini menggunakan Return On Assets atau yang biasa disingkat ROA sebagai alat ukur profitabilitas yaitu dengan membandingkan antara laba sebelum pajak dengan rata rata total asset BPR se Kabupaten Klungkung dalam bentuk persen. Return On Assets (ROA) dapat dirumuskan sebagai berikut menurut menurut Surat Edaran Bank Indonesia Nomor 3/30/DPNP tanggal 14 Desember 2001:

$\mathrm{ROA}=\left(\frac{\text { Laba Sebelum Pajak }}{\text { Rata Rata Total Aset }}\right) \times 100 \%$

Penelitian ini menggunakan rasio NPL (Non Performing Loan) untuk mengukur tingkat risiko kredit dari BPR se Kabupaten Klungkung. Menurut Peraturan Bank Indonesia Nomor 17/11/PBI/2015 NPL dirumuskan sebagai berikut :

$\mathrm{NPL}=\frac{\text { Kredit Bermasalah }}{\text { Total Kredit yang diberikan }} X 100 \%$

Penelitian ini menggunakan rasio LDR (Loan to Deposit Ratio) untuk mengukur tingkat likuiditas dari BPR se Kabupaten Klungkung. Menurut Surat 
Edaran Bank Indonesia Nomor 3/30/DPNP tanggal 14 Desember 2001 LDR dirumuskan sebagai berikut :

$\mathrm{LDR}=\left(\frac{\text { Kredit }}{\text { Dana Pihak Ketiga }}\right) \times 100 \%$

BOPO sebagai alat ukur efisiensi operasional yaitu dengan membandingkan biaya operasional dengan pendapatan operasional pada BPR se Kabupaten Klungkung pada periode 2013-2017 dalam satuan persentase. Menurut Susilowati (2017) BOPO dapat dirumuskan sebagai berikut :

$\mathrm{BOPO}=\frac{\text { Biaya Operasional }}{\text { Pendapatan Operasional }} \times 100 \%$

Pada penelitian ini data yang digunakan adalah data kuantitatif serta kualitatif. Sumber data dari penelitian ini yakni data sekunder. Sumber data yang digunakan pada penelitian ini adalah laporan keuangan pada BPR se Kabupaten Klungkung pada tahun 2013 - 2017 yang telah dipublikasi oleh www.bi.go.id

Populasi yang digunakan pada penelitian ini adalah BPR se Kabupaten Klungkung pada tahun 2013 hingga 2017 yang terdapat 5 BPR di Kabupaten Klungkung. Pada penelitian ini menggunakan metode sampling jenuh sebagai metode dalam penentuan sampel karena jumlah populasi dari suatu penelitian relatif kecil atau kurang dari 30.

Tabel 2.

Daftar Sampel Penelitian Periode 2013-2017

\begin{tabular}{cl}
\hline No. & \multicolumn{1}{c}{ Nama BPR } \\
\hline 1 & PT. BPR Tri Dharma Putri \\
2 & PT. BPR Artha Rengganis \\
3 & PT. BPR Sinar Puteramas \\
4 & PT. BPR Balaguna Perasta \\
5 & PT. BPR Sari Jaya Sedana d/h Acuta Jaya \\
\hline Sumber: & data diolah, 2018
\end{tabular}


Ni Putu Ayu Ria Agustini, Pengaruh Profitabilitas, Risiko Kredit, Likuiditas...

Dalam penelitian ini penelitian yang digunakan adalah teknik analisis regresi linier berganda sebagai teknik untuk pengolahan data. Dalam mengolah data pada analisis regresi linier berganda ini dibantu dengan SPSS. Untuk menguji model tersebut dapat menggunakan rumus :

$Y=\alpha+\beta_{1} X_{1}+\beta_{2} X_{2}+\beta_{3} X_{3}+\beta_{4} X_{4}+e$

Dimana keterangan adalah sebagai berikut :

$\mathrm{Y} \quad=$ Kecukupan Modal (CAR)

$\alpha \quad=$ Konstanta

$\beta_{1} \quad=$ Koefisien regresi dari Profitabilitas (X1)

$\beta_{2} \quad=$ Koefisien regresi dari Risiko Kredit (X2)

$\beta_{3} \quad=$ Koefisien regresi dari Likuiditas (X3)

$\beta_{4} \quad=$ Koefisien regresi dari Efisiensi Operasional (X4)

$X_{1}=$ Profitabilitas

$X_{2} \quad=$ Risiko Kredit

$X_{3} \quad=$ Likuiditas

$X_{4}=$ Efisiensi Operasional

$\mathrm{e} \quad=$ Standar Error

\section{HASIL DAN PEMBAHASAN}

Tabel 3.

Statistik Deskriptif Sampel Penelitian

\begin{tabular}{|c|c|c|c|c|c|}
\hline & $\mathbf{N}$ & Minimum & Maximum & Mean & $\begin{array}{c}\text { Std. } \\
\text { Deviation }\end{array}$ \\
\hline ROA & 25 & 0 & 3 & 2.66 & 0.632 \\
\hline NPL & 25 & 2 & 25 & 7.23 & 4.754 \\
\hline LDR & 25 & 54 & 96 & 83.95 & 8.901 \\
\hline BOPO & 25 & 82 & 99 & 86.26 & 3.429 \\
\hline CAR & 25 & 11 & 28 & 19.23 & 4.792 \\
\hline $\begin{array}{l}\text { Valid N } \\
\text { (listwise) }\end{array}$ & 25 & & & & \\
\hline
\end{tabular}

Berdasarkan Tabel 3, rata-rata ROA di BPR se Kabupaten Klungkung sebesar 2,66 persen dengan nilai ROA tertinggi sebesar 3 persen yang terjadi setiap tahun dari 2013 hingga 2017 dan nilai ROA terendah yang terjadi pada 
tahun 2016 yaitu sebesar 0 persen. rata-rata NPL di BPR se Kabupaten Klungkung sebesar 7,23 persen dan nilai NPL terbesar sebesar 25 persen pada tahun 2016 dan nilai NPL terkecil pada tahun 2013 dan 2014 yakni sebesar 2 persen. Rata-rata LDR di BPR se Kabupaten Klungkung sebesar 83,95 persen dan nilai LDR terbesar 96 persen pada tahun 2014 dan nilai LDR terkecil pada tahun 2013 yakni sebesar 54 persen. Rata-rata BOPO di BPR se Kabupaten Klungkung sebesar 86,26 persen dan nilai BOPO terbesar pada tahun 2016 yakni 99 persen dan nilai BOPO terkecil pada tahun 2015 yakni sebesar 82 persen. Rata-rata CAR di BPR se Kabupaten Klungkung sebesar 19,23 persen dengan nilai CAR terbesar yakni 28 persen pada tahun 2014 dan 2016 dan nilai CAR terkecil pada tahun 2013 yakni sebesar 11 persen.

Tabel 4.

Uji Normalitas

\begin{tabular}{cc}
\hline & Unstandardized Residual \\
\hline $\mathrm{N}$ & 25 \\
Asymp. Sig. (2-tailed) & 0,167 \\
\hline Sumber : Data Diolah, 2018
\end{tabular}

Jika dilihat dari Tabel 4 terlihat bahwa nilai Asymp. Sig. (2-tailed) adalah 0,167. Jika dibandingkan dengan taraf signifikansi yang sebesar 0,05 maka hasil tersebut memiliki nilai yang lebih besar sehingga dapat disimpulkan bahwa data yang dipergunakan telah memenuhi syarat normalitas atau berdistribusi normal.

Tabel 5.

Uji Autokorelasi

\begin{tabular}{cccccc}
\hline Model & $\boldsymbol{R}$ & $\boldsymbol{R}$ Square & $\begin{array}{c}\text { Adjusted } \boldsymbol{R} \\
\text { Square }\end{array}$ & $\begin{array}{c}\text { Std. Error of the } \\
\text { Estimate }\end{array}$ & $\begin{array}{c}\text { Durbin- } \\
\text { Watson }\end{array}$ \\
\hline 1 &, $896^{\mathrm{a}}$ &, 803 &, 764 & 2,32936 & 2,017
\end{tabular}

Sumber : Data Diolah, 2018 
Ni Putu Ayu Ria Agustini, Pengaruh Profitabilitas, Risiko Kredit, Likuiditas...

Pada tabel 5 menunjukkan bahwa nilai Durbin Watson sebesar 2,017. Penelitian ini menggunakan 25 sampel dan 4 variabel bebas sehingga nilai $\mathrm{d}_{\mathrm{U}}$ adalah 1,766 dan nilai 4-d adalah 2,234. Oleh karena nilai $\mathrm{d}_{\mathrm{U}}<\mathrm{DW}<4-\mathrm{d}_{\mathrm{U}}$ atau $1,766<2,017<2,234$, maka dapat disimpulkan bahwa tidak ada autokorelasi dalam penelitian ini.

Tabel 6.

Uji Multikolinieritas

\begin{tabular}{ccc}
\hline \multirow{2}{*}{ Model } & \multicolumn{2}{c}{ Colinierity Statistic } \\
\cline { 2 - 3 } & Tolerance & VIF \\
\hline ROA & 0,119 & 8,399 \\
NPL & 0.343 & 2,918 \\
LDR & 0,988 & 1,013 \\
BOPO & 0,192 & 5,200 \\
\hline Sumber $:$ Data
\end{tabular}

Tabel 6 menunjukkan bahwa koefisien Tolerance semua variabel lebih besar dari 0,10 dan nilai VIF yang lebih kecil dari 10 . Hasil tersebut menunjukkan bahwa tidak terdapat gejala multikolinieritas dalam model regresi yang dibuat.

Tabel 7.

Uji Heteroskedastisitas

\begin{tabular}{ccc}
\hline Model & Sig. & Keterangan \\
\hline ROA & 0,456 & Lolos Uji \\
NPL & 0,216 & Lolos Uji \\
LDR & 0,528 & Lolos Uji \\
BOPO & 0,625 & Lolos Uji \\
\hline
\end{tabular}

Sumber : Data Diolah, 2018 
Tabel 7 menunjukkan nilai signifikansi masing masing variabel bebas > 0,05, maka disimpulkan model regresi tersebut terbebas dari gejala heteroskedastisitas.

Tabel 8.

Uji Analisis Regresi Linier Berganda

\begin{tabular}{|c|c|c|c|c|c|}
\hline \multirow{2}{*}{ Model } & \multicolumn{2}{|c|}{ Unstandardized Coefficients } & \multirow{2}{*}{$\begin{array}{c}\begin{array}{c}\text { Standardized } \\
\text { Coefficients }\end{array} \\
\text { Beta } \\
\end{array}$} & \multirow{2}{*}{$t$} & \multirow{2}{*}{ Sig. } \\
\hline & $B$ & Std. Error & & & \\
\hline (Constant) & $-89,668$ & 32,694 & & $-2,743$ & 0,013 \\
\hline ROA & 5,602 & 2,179 & 0,739 & 2,571 & 0,018 \\
\hline NPL & 1,005 & 0,171 & 0,997 & 5,884 & 0,000 \\
\hline LDR & 0,191 & 0,054 & 0,354 & 3,548 & 0,002 \\
\hline BOPO & 0,819 & 0,316 & 0,586 & 2,591 & 0,017 \\
\hline $\mathrm{R}$ & 0,896 & & & & \\
\hline $\mathrm{R}^{2}$ & 0,803 & & & & \\
\hline Adjusted $\mathrm{R}^{2}$ & 0,764 & & & & \\
\hline F hitung & 20,401 & & & & \\
\hline Sig. F & 0,000 & & & & \\
\hline
\end{tabular}

Dilihat dari tabel 8 dapat diperoleh persamaan regresi linier berganda sebagai berikut:

$Y=-89,668+5,602 X_{1}+1,005 X_{2}+0,191 X_{3}+0,819 X_{4}$

Dari tabel 8 dan persamaan regresi diatas dapat dijelaskan sebagai berikut:

1) Persamaan regresi diatas menunjukan nilai konstanta sebesar $-89,668$ yang menunjukkan jika variabel independen diasumsikan konstan maka variabel kecukupan modal sebesar 89,668 persen. 2) Variabel profitabilitas ( $\left.\mathrm{X}_{1}\right)$ mempunyai koefisien 5,602 dengan arah positif. Menandakan jika profitabilitas meningkat 1 persen dan variabel independen lainnya konstan maka kecukupan modal akan meningkat sebesar 5,602 persen. 3) Variabel risiko kredit $\left(\mathrm{X}_{2}\right)$ mempunyai koefisien 1,005 dengan arah positif. Menandakan jika nilai risiko 
Ni Putu Ayu Ria Agustini, Pengaruh Profitabilitas, Risiko Kredit, Likuiditas...

kreditnya meningkat 1 persen dan variabel independen lain konstan maka kecukupan modal akan meningkat sebesar 1,005 persen. 4) Variabel likuiditas $\left(\mathrm{X}_{3}\right)$ mempunyai koefisien 0,191 dengan arah positif. Menandakan jika nilai likuiditasnya meningkat 1 persen dan variabel independen lainnya konstan maka kecukupan modal akan meningkat sebesar 0,191 persen. 5) Variabel efisiensi operasional $\left(\mathrm{X}_{4}\right)$ mempunyai koefisien 0,819 dengan arah positif. Menandakan apabila nilai efisiensi operasionalnya meningkat 1 persen dan variabel independen lainnya konstan maka kecukupan modal meningkat sebesar 0,819 persen.

Tabel 9.

Uji t

\begin{tabular}{|c|c|c|c|c|c|c|}
\hline & \multirow{2}{*}{ Model } & \multicolumn{2}{|c|}{$\begin{array}{c}\text { Unstandardized } \\
\text { Coefficients }\end{array}$} & \multirow{2}{*}{$\begin{array}{c}\begin{array}{c}\text { Standardized } \\
\text { Coefficients }\end{array} \\
\text { Beta }\end{array}$} & \multirow{2}{*}{$T$} & \multirow{2}{*}{ Sig. } \\
\hline & & $\boldsymbol{B}$ & $\begin{array}{c}\text { Std. } \\
\text { Error }\end{array}$ & & & \\
\hline \multirow{5}{*}{1} & (Constant) & $-89,668$ & 32,694 & & $-2,743$ & ,013 \\
\hline & ROA & 5,602 & 2,179 & 0,739 & 2,571 & ,018 \\
\hline & NPL & 1,005 & 0,171 & 0,997 & 5,884 & ,000 \\
\hline & LDR & 0,191 & 0,054 & 0,354 & 3,548 & ,002 \\
\hline & BOPO & 0,819 & 0,316 & 0,586 & 2,591 &, 017 \\
\hline
\end{tabular}

Sumber : Data Diolah, 2018

Dapat dilihat bahwa nilai $t$ hitung variabel ROA lebih besar dari $t$ tabel $(2,571>2,080)$ dan nilai signifikansinya 0,018 lebih kecil dari 0,05 . Hasil ini menunjukan bahwa profitabilitas yang diwakili oleh ROA berpengaruh positif dan signifikan terhadap kecukupan modal yang diwakilkan dengan CAR.

Dapat dilihat bahwa nilai t hitung variabel NPL lebih besar dari t tabel $(5,884>2,080)$ dan nilai signifikansinya 0,000 yang lebih kecil dari 0,05 . Hasil 
ini menunjukkan bahwa risiko kredit yang diwakilkan oleh NPL berpengaruh positif dan signifikan terhadap kecukupan modal yang diwakilkan dengan CAR.

Dapat dilihat bahwa nilai $t$ hitung variabel LDR lebih besar dari $t$ tabel $(3,548>2,080)$ dan nilai signifikansinya 0,002 lebih kecil dari 0,05. Hasil ini menunjukkan bahwa likuiditas yang diwakilkan oleh LDR berpengaruh positif dan signifikan terhadap kecukupan modal yang diwakilkan dengan CAR

Dapat dilihat bahwa nilai t hitung variabel BOPO lebih besar dari t tabel $(2,591<2,080)$ dan nilai signifikansinya 0,017 lebih kecil dari 0,05 . Hasil ini menunjukkan bahwa efisiensi operasional yang diwakilkan oleh BOPO berpengaruh positif dan signifikan terhadap kecukupan modal yang diwakilkan dengan CAR.

Tabel 10.

Uji F

\begin{tabular}{|c|c|c|c|c|c|c|}
\hline \multicolumn{2}{|r|}{ Model } & $\begin{array}{l}\text { Sum of } \\
\text { Squares }\end{array}$ & $D f$ & $\begin{array}{c}\text { Mean } \\
\text { Square }\end{array}$ & $F$ & Sig. \\
\hline \multirow{3}{*}{1} & Regression & 442,770 & 4 & 110,693 & 20,401 & 000 \\
\hline & Residual & 108,518 & 20 & 5,426 & & \\
\hline & Total & 551,289 & 24 & & & \\
\hline
\end{tabular}

Hasil uji nilai signifikansi $\mathrm{F}$ adalah sebesar 0,000 yang lebih kecil dari 0,05 $(\mathrm{F}<\alpha)$ yang dimana menandakan variabel independen berpengaruh signifikan secara serempak atau bersama-sama terhadap variabel dependen, sehingga penelitian ini dapat dikatakan memenuhi uji kelayakan model atau model penelitian dinyatakan layak digunakan sebagai model regresi. 
Tabel 11.

Koefisien Determinasi

\begin{tabular}{ccccc}
\hline Model & $\boldsymbol{R}$ & $\boldsymbol{R}$ Square & $\begin{array}{c}\text { Adjusted } \\
\boldsymbol{R} \text { Square }\end{array}$ & $\begin{array}{c}\text { Std. Error of the } \\
\text { Estimate }\end{array}$ \\
\hline 1 &, 896 &, 803 &, 764 & 2,32936 \\
\hline Sumber : Data Diolah, 2018 & & &
\end{tabular}

Besarnya nilai adjusted $\mathrm{R}$ square adalah sebesar 0,764 yang artinya sebesar 76,4 persen variasi kecukupan modal dipengaruhi oleh profitabilitas, risiko kredit, likuiditas dan efisiensi operasional sedangkan sisanya sebesar 23,6 persen dipengaruhi oleh faktor-faktor lain yang tidak dimasukkan kedalam model penelitian.

Berdasarkan hasil uji t diatas variabel profitabilitas yang diwakilkan oleh ROA memperoleh nilai t hitung sebesar 2,571 dengan signifikansi 0.018 , serta $\mathrm{t}$ tabel sebesar 2,080. Karena nilai signifikansi lebih kecil daripada 0,05 dan nilai t hitung lebih besar daripada $\mathrm{t}$ tabel maka dapat disimpulkan bahwa ROA berpengaruh positif signifikan terhadap CAR sehingga hipotesis yang diajukan yaitu ROA memiliki pengaruh positif dan signifikan terhadap CAR diterima. Pengaruh positif yang ditunjukkan oleh ROA mengindikasikan bahwa apabila ROA pada BPR se Kabupaten Klungkung mengalami kenaikan maka CAR pada BPR se Kabupaten Klungkung akan mengalami kenaikan, dan begitu pula sebaliknya. Nilai ROA pada BPR Se Kabupaten Klungkung periode 2013-2017 terbilang sehat dikarenakan diatas $1,25 \%$ yakni berkisar antara $2 \%$ hingga $3 \%$. Hal tersebut menandakan semakin tinggi nilai ROA yang dihasilkan oleh BPR se Kabupaten Klungkung menunjukkan bahwa BPR se Kabupaten Klungkung 
mampu memberikan keuntungan sebelum bunga dan pajak berdasarkan asetnya, maka cadangan modal yang mampu dihasilkan berdasarkan keuntungan tersebut semakin besar.

Hasil penelitian ini mendukung hasil penelitian yang dilakukan oleh Shaddady dan Moore (2015), Aktas et al. (2015), Wen (2007), Mekonnen (2015), Fitrianto \& Mawardi (2006), Yuanjuan (2012) mendapatkan hasil yakni profitabilitas memiliki pengaruh positif signifikan terhadap kecukupan modal.

Berdasarkan hasil uji t, risiko kredit yang diwakili oleh NPL memiliki nilai t hitung yang lebih besar dari t tabel $(5,884>2,080)$ dengan nilai signifikansi 0,000 yang lebih kecil dari 0,05 . Sehingga dapat disimpulkan bahwa risiko kredit yang di wakili oleh NPL berpengaruh positif signifikan terhadap kecukupan modal yang diwakili oleh CAR. Apabila NPL meningkat maka CAR juga mengalami peningkatan dan begitu pula sebaliknya. Hasil tersebut menunjukkan bahwa hipotesis 2 ditolak. Hal ini disebabkan karena kondisi BPR se Kabupaten Klungkung memiliki keadaan yang berbeda dengan teori. Jika dilihat dari kondisi BPR se Kabupaten Klungkung, adanya beberapa bank yang memiliki kredit macet atau NPL yang cukup tinggi dengan nilai CAR atau kecukupan modalnya juga tinggi. Hal ini bisa terjadi karena bunga pinjaman dan tabungan BPR besar, jadi walaupun risiko kreditnya meningkat, maka pendapatan yang didapat dari bunga pinjaman dan tabungan dapat digunakan untuk memenuhi kebutuhan modal BPR se Kabupaten Klungkung. Selain itu bertambahnya beberapa komponen modal bank yakni pada modal pelengkap ataupun modal inti juga dapat menutupi kredit macet. 
Ni Putu Ayu Ria Agustini, Pengaruh Profitabilitas, Risiko Kredit, Likuiditas...

Hasil penelitian ini mendukung hasil penelitian yang dilakukan oleh Bukian (2016) dan Torki \& Ghazi (2015) yang mendapatkan hasil yaitu risiko kredit memiliki pengaruh positif signifikan terhadap kecukupan modal.

Berdasarkan hasil uji t, diketahui bahwa likuiditas yang diwakili oleh LDR memiliki nilai t hitung yang lebih besar dari t tabel $(3,548>2,080)$ dengan nilai signifikansi 0,002 yang lebih kecil dari 0,05. Hasil ini menunjukkan bahwa likuiditas yang diwakilkan oleh LDR berpengaruh positif dan signifikan terhadap kecukupan modal yang diwakilkan dengan CAR. Apabila LDR meningkat maka CAR juga mengalami peningkatan dan begitu pula sebaliknya. Hasil tersebut menunjukkan bahwa hipotesis 3 yakni likuiditas memiliki pengaruh negatif signifikan terhadap CAR diterima. Likuiditas memiliki pengaruh positif terhadap kecukupan modal menandakan bahwa semakin tinggi nilai likuiditas menandakan semakin banyak cash yang diterima bank dan bank dapat memberikan kredit yang lebih banyak kepada masyarakat dan meningkatnya kredit yang diberikan maka pendapatan bunga yang didapat akan meningkat. Pemenuhan modal juga bisa didapat dari pendapatan bunga.

Hasil penelitian ini mendukung hasil penelitian yang dilakukan oleh Bukian (2016), Maolany (2015), Al Tamimi \& Obeidat (2013), Torki \& Ghazi (2015) mendapatkan hasil likuiditas memiliki pengaruh positif signifikan terhadap kecukupan modal.

Berdasarkan hasil uji t, diketahui bahwa efisiensi operasional yang diwakili oleh BOPO memiliki nilai t hitung yang lebih besar dari t tabel $(2,591<2,080)$ dan nilai signifikansi 0,017 lebih kecil dari 0,05. Hasil ini menunjukkan bahwa 
efisiensi operasional yang diwakilkan oleh BOPO berpengaruh positif dan signifikan terhadap kecukupan modal yang diwakilkan dengan CAR. Hasil tersebut menunjukkan bahwa hipotesis 4 yakni efisiensi operasional memiliki pengaruh negatif signifikan terhadap CAR ditolak. Efisiensi operasional berpengaruh positif signifikan terhadap CAR jika dilihat pada tingkat signifikansi dari BOPO yang kurang dari 0,05. Hal ini bisa saja terjadi dikarenakan BPR se Kabupaten Klungkung tidak bisa mengontrol biaya operasionalnya dengan efisien sehingga memakan pendapatan operasional beserta keuntungan yang dimiliki. Bank menjadi menjual asetnya sebelum menyentuh modal. Karena saat mendapat kelebihan dari hasil penjualan asset merupakan pendapatan non operasional, kelebihan ini dapat masuk ke dalam modal yang kedepannya bisa digunakan untuk membeli asset bank.

Hasil pada penelitian ini mendukung dari hasil penelitian yang dilakukan oleh Fatimah (2014), Chatarine (2014) mengatakan bahwa efiensi operasional berpengaruh positif signifikan terhadap kecukupan modal.

Berdasarkan pembahasan pada penelitian ini dapat memberikan implikasi bahwa profitabilitas, risiko kredit, likuiditas, dan efisiensi operasional mempunyai pengaruh yang signifikan terhadap kecukupan modal pada Bank BPR se Kabupaten Klungkung. Peningkatan atau penurunan dari profitabilitas, risiko kredit, likuiditas, dan efisiensi operasional akan mempengaruhi besarnya tingkat ,kecukupan modal yang didapat oleh bank. Penelitian ini menunjukkan bahwa selain mempunyai peran penting dalam meningkatkan kecukupan modalnya, profitabilitas, risiko kredit, likuiditas, dan efisiensi operasional juga dapat 
Ni Putu Ayu Ria Agustini, Pengaruh Profitabilitas, Risiko Kredit, Likuiditas...

memberikan informasi dan masukan bagi Bank Perkreditan Rakyat (BPR) dan pihak-pihak lainnya agar dapat membuat keputusan yang tepat terkait dengan tingkat kecukupan modal agar bank bias berjalan dengan baik.

\section{SIMPULAN DAN SARAN}

Berdasarkan hasil pembahasan yang telah diuraikan pada bab sebelumnya, maka diperoleh simpulan sebagai berikut : 1) Profitabilitas berpengaruh positif dan signifikan terhadap kecukupan modal. Hal tersebut menandakan semakin tinggi nilai ROA yang dihasilkan oleh BPR se Kabupaten Klungkung menunjukkan bahwa BPR se Kabupaten Klungkung mampu memberikan keuntungan sebelum bunga dan pajak berdasarkan asetnya, maka cadangan modal yang mampu dihasilkan berdasarkan keuntungan tersebut semakin besar. 2) Risiko kredit berpengaruh positif dan signifikan terhadap kecukupan modal. Hal ini bisa terjadi karena bunga pinjaman dan tabungan BPR besar, jadi walaupun risiko kreditnya meningkat, maka pendapatan yang didapat dari bunga pinjaman dan tabungan dapat digunakan untuk memenuhi kebutuhan modal BPR se Kabupaten Klungkung. 3) Likuiditas berpengaruh positif signifikan terhadap kecukupan modal. Hal ini bisa terjadi karena meningkatnya jumlah penyaluran kredit yang dilakukan oleh BPR se Kabupaten Klungkung dan hal tersebut menyebabkan pendapatan bunga kredit yang diperoleh bank meningkat dan digunakan untuk memenuhi modal bank. 4) Efisiensi operasional berpengaruh positif signifikan terhadap kecukupan modal. Hal ini bisa terjadi karena BPR se Kabupaten Klungkung menjual asetnya karena tidak dapat mengendalikan biaya operasional dengan baik. Disaat bank terdapat kelebihan dari hasil penjualan 
asset, kelebihan ini merupakan pendapatan non operasional yang bisa dimasukkan kembali kedalam modal.

Saran yang dapat diberikan bagi pihak BPR 1) Profitabilitas yang diwakili oleh ROA berpengaruh positif signifikan terhadap kecukupan modal yang diwakili oleh CAR, maka kepada pihak BPR se Kabupaten Klungkung disarankan untuk terus menjaga dan meningkatkan kecukupan modalnya melalui profit yang didapat 2) Risiko kredit yang diwakilkan dengan NPL berpengaruh positif signifikan terhadap kecukupan modal yang diwakilkan dengan CAR, maka kepada pihak BPR se Kabupaten Klungkung karena memiliki nilai NPL yang tinggi disarankan agar selalu berhati hati didalam memberikan nasabah pinjaman agar nantinya kredit macet tidak terjadi. 3) Likuiditas yang dalam penelitian ini diwakilkan dengan LDR berpengaruh positif signifikan terhadap kecukupan modal yang diwakilkan dengan CAR, maka kepada pihak BPR se Kabupaten Klungkung disarankan untuk menyalurkan lebih banyak kredit agar meningkatkan kecukupan modalnya. 4) Efisiensi operasional yang dalam penelitian ini diwakilkan dengan BOPO berpengaruh terhadap kecukupan modal yang diwakilkan oleh CAR, maka pihak BPR se Kabupaten Klungkung disarankan untuk menekan biaya operasional agar dapat memiliki keuntungan yang lebih besar dan dapat menambah kecukupan modal BPR se Kabupaten Klungkung agar dapat menjalankan kewajibannya dengan baik, efektif dan efisien. Dan bagi peneliti selanjutnya yang akan melakukan penelitian mengenai kecukupan modal sebaiknya menggunakan tahun atau periode yang lebih lama dan variabel lain selain didalam penelitian ini supaya mendapatkan hasil yang lebih baik. 


\section{REFERENSI}

Abusharba, Mohammed. T, Iwan Triyuwono, Munawar Ismail dan Aulia F. Rahman. 2013. Determinants of Capital Adequacy Ratio (CAR) in Indonesian Islamic Commercial Banks. Global Review of Accounting and Finance, 4(1): h: 159-170.

Aktas Rafet, Acikalin Suleyman, Bakin Bilge, Celik Gokhan. 2015. The Determinants of Banks' Capital Adequacy Ratio : Some Evidence from South Eastern European Countries. Journal Economics and Behavioral Studies, 7(1), pp. 79-88.

Al-Tamimi, Khaled dan Samer Fakhri. 2013. Determinants of Capital Adequacy in Commercial Banks of Jordan an Empirical Study. International Journal of Academic Research in Economics and Management Sciences, 2(4), pp: 44-58.

Andersson, Mattias dan Isabell Nordenhager. 2013. The Impact Of Basel II Regulation In The European Banking Market. International Journal of Financial, 5(1), pp: 1-45.

Anjani, Dewa Ayu dan Ni Ketut Purnawati. 2014. Pengaruh non performing loan (NPL),Likuiditas dan Rentabilitas Terhadap Rasio Kecukupan Modal. EJurnal Manajemen Universitas Udayana,3 (4) hal.1140-1154.

Ariwidanta, Komang Triska. 2016. Pengaruh Risiko Kredit Terhadap Profitabilitas Dengan Kecukupan Modal Sebagai Variabel Mediasi. EJurnal Manajemen Universitas Udayana,5 (4), hal.2311-2340

Basse, Intannes Putri dan Mulazid, Ade Sofyan. 2017. Analisa Pengaruh Kualitas Aset, Likuiditas, Efensiesi Usaha, dan Profitabilitas terhadap Rasio Kecukupan Modal pada Bank Umum Syariah Periode 2012 - 2015. AlTijary Jurnal Ekonomi dan Bisnis Islam.2(2).hal. 209-123

Budisantoso, Totok dan Nuritomo.2014. Bank dan Lembaga Keuangan Lain. Jakarta: Salemba Empat.

Budisantoso, Totok dan Nuritomo.2015. Bank dan Lembaga Keuangan Lain. Edisi 3. Jakarta: Salemba Empat

Bukian, Ni Made Winda Parascintya, dan Gede Merta Sudiartha. 2016. Pengaruh Kualitas Aset, Likuiditas, Rentabilitas Dan Efisiensi Operasional 
Terhadap Rasio Kecukupan Modal.E-Jurnal Manajemen Unud, 5 (2), hal.1189-1221.

Capriani, Ni Wayan Wita dan Dana, I Made.2016.Pengaruh Risiko Kredit Risiko Operasional dan Risiko Likuiditas Terhadap Profitabilitas BPR di Kota Denpasar.E-Jurnal Manajemen Unud, 5(3), hal. 1486 -1512.

Chatarine, Alvita. 2014. Pengaruh Kualitas Aktiva Produktif, BOPO terhadap ROA dan CAR pada BPR Kabupaten Badung. E-Jurnal Manajemen Unud.3 (3), hal. 561-577

Darmawi, Hermawan. 2014. Manajemen Perbankan. Cetakan Ketiga. Jakarta: Bumi Aksara

Fahmi Irham. 2016. Bank dan Lembaga Keuangan Lainnya Teori dan Aplikasi. Bandung: Alfabeta

Fatimah, Siti. 2014. Pengaruh Rentabilitas, Efisiensi, dan Likuiditas Terhadap Kecukupan Modal Bank Umum Syariah.Journal of Islamic Economics, 6 (1), hal 42-58

Fitrianto, Hendra dan Wisnu Mawardi. 2006. Analisis Pengaruh Kualitas Aset, Likuiditas, Rentabilitas dan Efisiensi Terhadap Rasio Kecukupan Modal Perbankan yang Terdaftar di Bursa Efek Jakarta. Jurnal Studi Manajemen dan Organisasi, 3 (1), hal.1-11.

Ghazi, A.Alrgaibat \& Torki, M.Al-Fawwaz. 2015. Capital Adequacy of the Jordanian Banking Sector for the Period 2000-2013. International Journal of Academic Research in Accounting, Finance and Management Sciences.5 (1), pp. 179-189

Ghozali, Imam. 2011. Aplikasi Analisis Multivarite dengan SPSS.Semarang : Badan Penerbit Universitas Diponogoro.

Gunawan, Imam. 2016. Pengantar Statistika Inferensial. Jakarta: Rajawali Pers.

Kasmir.2013.Manajemen Perbankan. Jakarta :Raja Grafindo Persada.

Kasmir.2015. Bank dan Lembaga Keuangan lainnya. Edisi Revisi 2014.Jakarta : Rajawali Pers.

Kasmir.2015. Manajemen Perbankan. Jakarta: Rajawali Pers. 
Ni Putu Ayu Ria Agustini, Pengaruh Profitabilitas, Risiko Kredit, Likuiditas...

Kasmir.2016. Dasar Dasar Perbankan. Edisi Revisi 2014. Rajawali Pers.Jakarta

Kasmir.2017. Analisis Laporan Keuangan. Cetakan Kesepuluh. Jakarta: Rajawali Pers.

Latumaerissa, Julius.R. 2017. Bank Dan Lembaga Keuangan Lain. Edisi Pertama. Jakarta: Mitra Wacana Media

Maolany, Moch Rizal dan Nurhayati.2015. Pengaruh Likuiditas dan Profitabilitas Terhadap Kecukupan Modal Pada Bank Mandiri Syariah Periode 2008 - 2013. Jurnal Universitas Islam Bandung, 1 (1), h: 172-179

Margaretha, Farah dan Diana Setiyaningrum. 2011. Pengaruh Resiko, Kualitas Manajemen, Ukuran dan Likuiditas Bank terhadap Capital Adequacy Ratio Bank - Bank yang Terdaftar di Bursa Efek Indonesia. Jurnal Akuntansi dan Keuangan, 13 (1), h: 47-56.

Mekonnen, Yonas. 2015. Determinants of Capital Adequacy of Ethiopia Commercial Banks.European Scientific Journal, 11(25). Pp 315-331

Natasia Rizky. 2015. Pengaruh Risiko Kredit, Profitabilitas, Loan to Deposit Ratio, Dan Efisiensi Usaha Terhadap Kecukupan Modal Pada Bank Yang Terdaftar Di Bursa Efek Indonesia Periode 2010-2014. E-Jurnal Ekonomi dan Bisnis.3 (3).hal.1-24.

Pasiouras, F.; Gaganis, C. \& Zopounidis, C. 2006. The Impact of Bank Regulations, Super-vision, Market Structure, and Bank Charac-teristics on Individual Bank Rating: A Cross Country Analysis. Review Quarterly Financial Accounting. 27:403-438

Pastory, Dickson, and Marobhe Mutaju. 2013. The Influence of Capital Adequacy on Asset Quality Position of Banks in Tanzania. International Journal of Economics and Finance,5(2), pp: 179-194.

Peraturan Bank Indonesia Nomor 3/22/PBI/2001 Tentang Transparansi Kondisi Keuangan Bank.

Peraturan Bank Indonesia Nomor 8/18/PBI/2006 Tentang Kewajiban Penyediaan Modal Minimum Bank Perkreditan Rakyat

Peraturan Bank Indonesia Nomor 13/1/PBI/2011 Tentang Penilaian Tingkat Kesehatan Bank Umum

Peraturan Bank Indonesia Nomor 14/18/PBI/2012 Tentang Kewajiban Penyediaan Modal Minimum Bank Umum 
Peraturan Bank Indonesia Nomor 17/11/PBI/2015 Tentang Perubahan atas Peraturan Bank Indonesia Nomor 15/15/PBI/2013 Tentang Giro Wajib Minimum Bank Umum dalam Rupiah Dan Valuta Asing Bagi Bank Umum Konvensional

Shaddady , Ali, and Moore, Tomoe. 2015. Determinants of Capital Adequacy Ratio in Oil Exporting Countries: Evidence from GCC Commercial Banks. Second Middle East Conference on Global Business, Economics, Finance and Banking (ME15 Dubai Conference), 22-24 May, 2015

Shingjergji, A.\& Hyseni, M., 2015. The Determinants of the Capital Adequacy Ratio in the Albanian Banking System During 2007 - 2014. International Journal of Economics, Commerce and Management, 3(1), pp.1-10.

Shitawati, F. Artin. 2006. Analisis Faktor - Faktor yang Berpengaruh Terhadap Capital Adequacy Ratio (Studi Empiris : Bank Umum di Indonesia periode 2001 - 2004). Tesis. Program Studi Magister Manajemen, Program Pasca Sarjana, Universitas Diponegoro. Semarang

Septiani, Rita dan Lestari, Putu Vivi.2016.Pengaruh NPL dan LDR Terhadap Profitabilitas Dengan CAR Sebagai Variabel Mediasi Pada PT BPR PASARRAYA KUTA.E-Jurnal Manajemen Unud, 5 (1), hal.293 -324.

SE BI No 3/30/ DPNP tgl 14 Desember 2001

Siregar, Syofian. 2010. Statistika Deskriptif untuk Penelitian: Dilengkapi Perhitungan Manual dan Aplikasi SPSS versi 17. Jakarta: PT. Raja Grafindo Persada.

SK DIR. NO.30/12/KEP/DIR tanggal 30 april 1997 Tentang Tatacara Penilaian Tingkat Kesehatan BPR

Surat Edaran Bank Indonesia No.15/7/DPNP tanggal 8 Maret 2013Perihal Pembukaan Jaringan Kantor Bank Umum Berdasarkan Modal Inti.

Sufian, F. (2011). Profitability of the Korean Banking Sector: Panel Evidence on Bank-Specific and Macroeconomic Determinants, Journal of Economics and Management, 7(1), pp:43-72. 
Ni Putu Ayu Ria Agustini, Pengaruh Profitabilitas, Risiko Kredit, Likuiditas...

Sujana, Putu Cahyadi dan Mustanda, I Ketut.2014.Pengaruh Cash Turnover, Loan To Deposit Ratio, Capital Adequacy Ratio, Dan Dana Pihak Ketiga Terhadap Profitabilitas LPD. E-Jurnal Manajemen Unud, 8(2). Hal.01108

Susilowati, Ni Made Novi, Purbawangsa, Ida Bagus Anom dan Artini, Luh Gede Sri. 2017.Variabel Variabel Pembeda Rasio Kecukupan Modal Bank Perkreditan Rakyat (BPR) Di Bali. E-Jurnal Ekonomi dan Bisnis Universitas Udayana.6(6), hal.2553-2586

Tracey, Mark. 2011. The Impact of Non-performing Loans on Loan Growth: an econometric cas study of Jamaica and Trinidad and Tobago, pp:1-22.

Undang Undang Nomor 10 Tahun 1998 tentang Perubahan atas Undang Undang Nomor 7 Tahun 1992 tentang Perbankan

Utari Dewi, Purwanti Ayu, Prawironegoro Darsono. 2014. Manajemen Keuangan. Edisi Revisi. Jakarta: Penerbit Mitra Wacana Media.

Veitthzal Rivai. 2013. Credit Management Handbook Manajemen Perkreditan cara Cara Mudah Menganalisis kredit. Jakarta: Rajagrafindo Persada.

Wen, Thiam Chiann. 2009. The Determinants of Bank Capital ratio in East Asia,Thesis, The Degree of Master of Business Administration University of Malaya.

Wiagustini, Ni Luh Putu. 2014. Manajemen Keuangan. Denpasar: Udayana University Press

Wiagustini, Luh Putu. 2010. Dasar - Dasar Manajemen Keuangan. Denpasar: Udayana University Press

Williams, Harley Tega. 2011. Determinants of Capital Adequacy in The Banking Sub-Sector of the Nigeria Economy: Efficacy of Camels. (A Model Specification with Co-Integration Analysis).International Journal of Academic Research in Business and Social Sciences, 1 (3), pp: 233248.

www.bi.go.id

Yuanjuan, Li dan Xiao Shishun. 2012. Effectiveness of China's Commercial Banks' Capital Adequacy Ratio. Interdisciplinary Journal Of Contemporary Research In Business, 4 (1),pp: 58-68. 
E-Jurnal Manajemen Unud, Vol. 7, No. 10, 2018: 5783-5813

Yuliani, Kadek Puspa, Werastuti, Desak Nyoman Tri dan Edy Sujana. 2015. Pengaruh Loan to Deposit Ratio (LDR), Non Performing Loan (NPL), Return On Asset (ROA) dan Biaya Operasional Terhadap Pendapatan Operasional (BOPO) Terhadap Capital Adequacy Ratio (CAR) (Studi Pada Bank Umum Swasta Nasional (BUSN) Devisa). e-JournalAk S1, Universitas Pendidikan Ganesha, 3(1). 